\title{
Definition and diagnostic criteria of sleep-related hypermotor epilepsy
}

\section{OPEN}

Paolo Tinuper, MD

Francesca Bisulli, MD, $\mathrm{PhD}$

J.H. Cross, MD, PhD

Dale Hesdorffer, PhD

Philippe Kahane, MD, $\mathrm{PhD}$

Lino Nobili, MD, PhD

Federica Provini, MD,

$\mathrm{PhD}$

Ingrid E. Scheffer, PhD, MBBS

Laura Tassi, MD

Luca Vignatelli, MD, PhD

Claudio Bassetti, MD

Fabio Cirignotta, MD

Christopher Derry, PhD

Antonio Gambardella, MD

Renzo Guerrini, MD

Peter Halasz, MD, PhD

Laura Licchetta, MD

Mark Mahowald, MD

Raffaele Manni, MD

Carla Marini, MD, PhD

Barbara Mostacci, MD, $\mathrm{PhD}$

Ilaria Naldi, MD, PhD

Liborio Parrino, MD, PhD

Fabienne Picard, MD

Maura Pugliatti, MD,

$\mathrm{PhD}$

Philippe Ryvlin, MD,

$\mathrm{PhD}$

Federico Vigevano, MD

Marco Zucconi, MD

Samuel Berkovic, MD,

FRS*

Ruth Ottman, $\mathrm{PhD}$ *

Correspondence to

Dr. Tinuper:

paolo.tinuper@unibo.it

Supplemental data at Neurology.org

\section{ABSTRACT}

The syndrome known as nocturnal frontal lobe epilepsy is recognized worldwide and has been studied in a wide range of clinical and scientific settings (epilepsy, sleep medicine, neurosurgery, pediatric neurology, epidemiology, genetics). Though uncommon, it is of considerable interest to practicing neurologists because of complexity in differential diagnosis from more common, benign sleep disorders such as parasomnias, or other disorders like psychogenic nonepileptic seizures. Moreover, misdiagnosis can have substantial adverse consequences on patients' lives. At present, there is no consensus definition of this disorder and disagreement persists about its core electroclinical features and the spectrum of etiologies involved. To improve the definition of the disorder and establish diagnostic criteria with levels of certainty, a consensus conference using formal recommended methodology was held in Bologna in September 2014. It was recommended that the name be changed to sleep-related hypermotor epilepsy (SHE), reflecting evidence that the attacks are associated with sleep rather than time of day, the seizures may arise from extrafrontal sites, and the motor aspects of the seizures are characteristic. The etiology may be genetic or due to structural pathology, but in most cases remains unknown. Diagnostic criteria were developed with 3 levels of certainty: witnessed (possible) SHE, video-documented (clinical) SHE, and video-EEG-documented (confirmed) SHE. The main research gaps involve epidemiology, pathophysiology, treatment, and prognosis. Neurology ${ }^{\circledR}$ 2016;86:1834-1842

\section{GLOSSARY}

ADSHE = autosomal dominant sleep-related hypermotor epilepsy; FFEVF = familial focal epilepsy with variable foci; $\mathbf{M F S I}=$ migrating focal seizures of infancy; $\mathbf{m T O R}=$ mammalian target of rapamycin; $\mathbf{n A C h R}=$ neuronal acetylcholine receptor; NFLE = nocturnal frontal lobe epilepsy; NREM = non-REM; PSG = polysomnography; SHE = sleep-related hypermotor epilepsy; SUDEP = sudden unexpected death in epilepsy

Nocturnal frontal lobe epilepsy (NFLE) was first described in 1981, in 5 patients with a peculiar motor disorder confined to sleep, characterized by violent limb movements or tonic-dystonic postures. ${ }^{1}$ Investigators debated for several years about whether this was an epileptic phenomenon or a new movement disorder.

Subsequently, similarity of the attacks to those in patients with frontal lobe epilepsy undergoing neurosurgical evaluation ${ }^{2,3}$ and demonstration of epileptiform discharges in some patients ${ }^{4}$

*These authors contributed equally to this work.

From IRCCS Istituto delle Scienze Neurologiche (P.T., F.B., F. Provini, L.V., L.L., B.M., I.N.), Bologna; Department of Biomedical and Neuromotor Sciences (P.T., F.B., F. Provini, L.L.), University of Bologna, Italy; University College London-Institute of Child Health (J.H.C.), Great Ormond Street Hospital for Children NHS Foundation Trust, London and Young Epilepsy, Lingfield, UK; Department of Epidemiology (D.H., R.O.), Mailman School of Public Health, and G.H. Sergievsky Center, College of Physicians \& Surgeons, Columbia University, New York, NY; Unité Médicale Epilepsie et Malaises (P.K.), Pôle de Neurologie et Psychiatrie, CHU de Grenoble, France; "C. Munari” Center for Epilepsy Surgery (L.N., L.T.), Niguarda Hospital, Milan, Italy; Epilepsy Research Centre (I.E.S.), Department of Medicine, University of Melbourne, Austin Health, Australia; Department of Neurology (C.B.), University of Bern, Switzerland; Unit of Neurology (F.C.), S. Orsola-Malpighi Hospital, University of Bologna, Italy; Department of Clinical Neurosciences (C.D.), Western General Hospital, Edinburgh, UK; Department of Medical and Surgical Sciences (A.G.), Institute of Neurology, University Magna Græcia, Catanzaro, Italy; Neurology Unit and Laboratories (R.G., C.M.), A. Meyer Children's Hospital, Florence, Italy; National Institute of Clinical Neuroscience (P.H.), Budapest, Hungary; Department of Neurology (M.M.), University of Minnesota Medical School, Minneapolis; Institute of Neurology Mondino (R.M.), University of Pavia; Sleep Disorders Center (L.P.), Department of Neurology, University of Parma, Italy; Department of Neurology (F. Picard), University Hospital and Medical School of Geneva, Switzerland; Department of Biomedical and Surgical Sciences (M.P.), University of Ferrara, Italy; Department of Clinical Neurosciences (P.R.), CHUV, Lausanne, Switzerland; Functional Neurology and Epileptology (P.R.), Hospices Civils de Lyon and CRNL, Lyon; Epilepsy Institute (P.R.), IDEE, Lyon, France; Division of Neurology (F.V.), Bambin Gesù Children's Hospital, IRCCS, Rome; Sleep Disorders Centre (M.Z.), Department of Clinical Neurosciences, San Raffaele Institute and Hospital, Milan, Italy; Epilepsy Research Centre (S.B.), Department of Medicine, University of Melbourne, Austin Health, Australia; and Department of Neurology (R.O.), College of Physicians \& Surgeons, Columbia University, New York, NY.

Go to Neurology.org for full disclosures. Funding information and disclosures deemed relevant by the authors, if any, are provided at the end of the article. The Article Processing Charge was paid by the authors.

This is an open access article distributed under the terms of the Creative Commons Attribution-NonCommercial-NoDerivatives License 4.0 (CC BYNC-ND), which permits downloading and sharing the work provided it is properly cited. The work cannot be changed in any way or used commercially. 
strongly suggested that these attacks were epileptic seizures. Insights into the biology occurred with the discovery of an autosomal dominant form ${ }^{5}$ and identification of the first gene, CHRNA4, encoding a neuronal nicotinic receptor subunit. ${ }^{6}$

This disorder is of interest to a broad spectrum of specialists, from child neurologists to neurosurgeons. Distinction from nonepileptic paroxysmal behaviour occurring physiologically or pathologically during sleep is often difficult or impossible on clinical grounds alone, and misdiagnosis is common. ${ }^{5,7}$ Poor recognition and misdiagnosis have multiple negative consequences, including unnecessary, costly investigations, ineffective and potentially harmful therapeutic regimens, and adverse psychosocial effects of erroneous epilepsy diagnosis.

Today, disagreement persists on key clinical features and criteria needed for diagnosis. Thus, a consensus development conference including experts in adult and pediatric epileptology, sleep medicine, and epidemiology was convened in Bologna on August 30-September 1, 2014. The aims of the conference were to (1) define the clinical features of the disorder, (2) define the electroclinical characteristics of the seizures, (3) establish diagnostic criteria with levels of certainty, (4) assess evidence for etiology, and (5) define research needs.

METHODS The method was inspired by the US NIH Consensus Development Program (http://consensus.nih.gov) and adapted from the Methodological Handbook of the Italian National Guideline System. ${ }^{8}$ The consensus conference method is recommended for addressing important clinical questions in the face of limited high-quality evidence. The main outcome, a consensus statement, represents the collective opinions of an expert panel, derived from systematic review and discussion of available evidence. ${ }^{9}$ The Bologna Consensus Conference was organized by the Istituto di Ricovero e Cura a Carattere Scientifico (IRCCS) delle Scienze Neurologiche di Bologna, Italy. Planning and execution was carried out in 4 phases: (1) assignment, (2) scoping, (3) assessment, and (4) the consensus conference itself. All activities were completed between November 2013 and September 2014.

The project included 4 entities: (1) the Scientific Committee (5 members) planned and organized the whole project, nominated Consensus Development Panel and Workgroup members, performed the systematic review with evidence mapping, chose the questions to be answered by the Workgroups, and established methods and rules of the Consensus Conference; (2) the Systematic Review and Technical Committee ( 4 members) assisted with defining questions and the systematic review with evidence mapping; (3) 3 Workgroups of experts ( 5 members each), each focused on 1 relevant topic, synthesized and integrated information from the systematic review before the consensus conference, provided shared answers to the proposed questions, and presented their findings during the Consensus Conference; (4) the Consensus Development Panel (8 members) chaired the Consensus Conference, established review and presentation procedures, and provided final statements.

The systematic review was performed according to accepted criteria for the conduct and reporting of systematic reviews ${ }^{\mathrm{e}}$ and reported according to PRISMA guidelines. ${ }^{\text {e2 }}$ The descriptive map of available research evidence (i.e., evidence mapping) was performed by adapting the methodology reported by the Global Evidence Mapping Initiative, ${ }^{\mathrm{e} 3}$ which involved detailed coding of included studies and a series of in-depth syntheses in which the available research was assessed in terms of, e.g., study design, number of patients, and topic.

Studies eligible for inclusion in evidence mapping. Published studies of any design, written in English, Italian, French, or Spanish, were included. Studies were included if they reported original data on patients with any type of motor complex behavior during sleep of epileptic origin with possible frontal lobe involvement. Reviews or concept papers and studies published only in abstract form were excluded.

Search strategy. Published studies were identified from the National Library of Medicine's MEDLINE database, Elsevier's EMBASE database, or the Cochrane Central Register of Controlled Trials by means of specific search strategies, using a combination of exploded terms and free text combining 3 concepts: motor phenomena in sleep, epilepsy, frontal lobe involvement (see appendix e-1 on the Neurology ${ }^{\circledR}$ Web site at Neurology.org for details). Finally, reference lists of identified articles were reviewed to find additional references.

Study selection and quality appraisal. All abstracts or full papers without electronic abstracts were reviewed independently by 2 reviewers to identify potentially relevant studies. Disagreement was resolved by a third reviewer. Subsequently, 2 reviewers independently assessed studies for inclusion from the full text, with disagreements resolved by a third reviewer. Each study was classified according to various descriptors (see appendix e-1), including topic domain, sample size, design, presence of diagnostic criteria of the syndrome, and quality of evidence according to the Classification of Evidence Schemes of the Clinical Practice Guideline Process Manual of the American Academy of Neurology (2011). ${ }^{\mathrm{e} 4}$ Briefly, each study is graded according to its risk of bias from Class I (highest quality) to Class IV (lowest quality). Risk of bias is judged by assessing specific quality elements (i.e., study design, patient spectrum, data collection, masking) for each clinical topic (causation, diagnostic accuracy, prognostic accuracy, therapeutic). As this classification does not consider molecular genetic studies, these were assessed using the checklist proposed for molecular studies from the Clinical Genetics Society, ${ }^{\text {e5 }}$ which also provides a 4-level classification scheme with decreasing quality from 1 to 4 by assessing specific quality elements (e.g., study design, evidence of altered function of a gene product, evidence of genomic structure conserved across species). This classification was performed by 3 reviewers, with disagreement resolved by discussion.

SYSTEMATIC REVIEW WITH EVIDENCE MAPPING The literature search was performed in December 2013 and April 2014, and retrieved 1,540 citations after duplicate removal (figure). Each retrieved article was screened to assess potential relevance, and 
Figure Preferred Reporting Items for Systematic Reviews and Meta-Analyses flow diagrame2

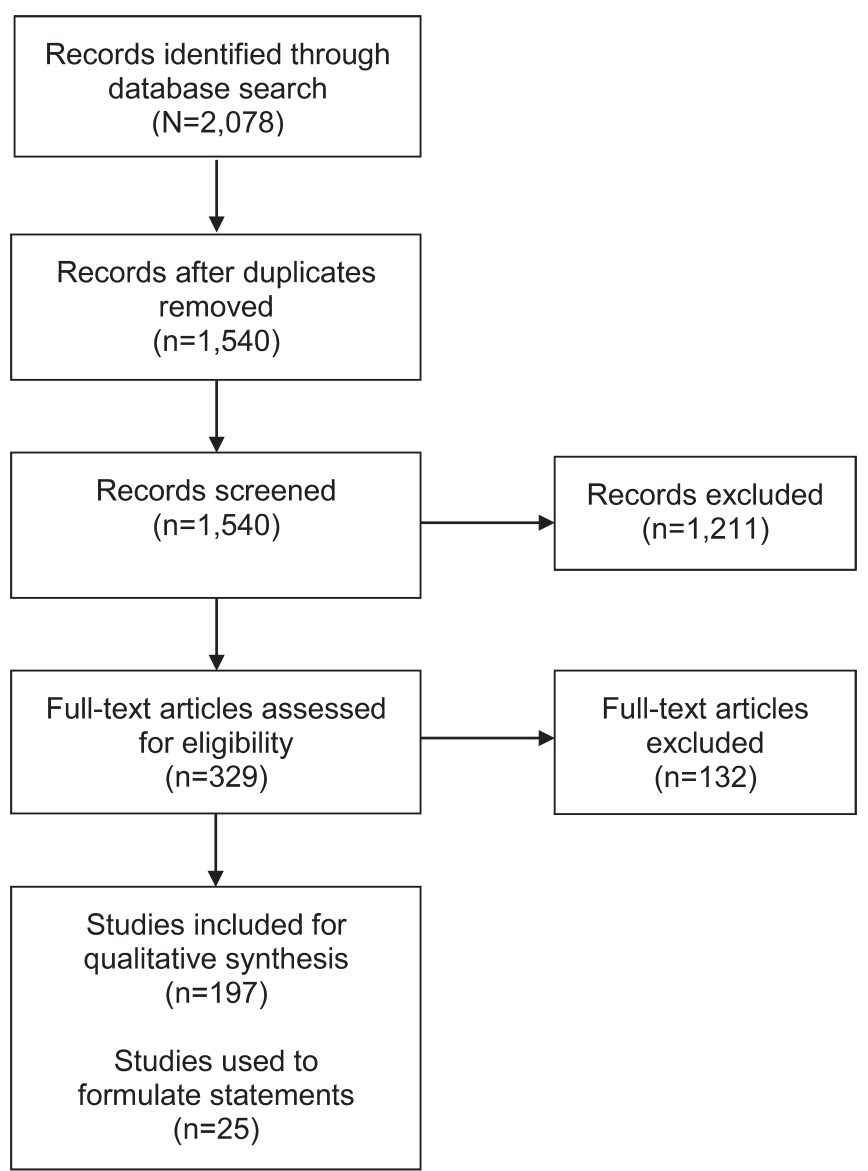

Process and result of the systematic search for studies on nocturnal frontal lobe epilepsy.

329 were reviewed from the full text for inclusion. A total of 197 studies finally met the prespecified inclusion criteria. See appendix e-1 for bibliometric details.

According to simple descriptors (table), the majority of studies were of low quality. Most included fewer than 10 patients $(57 \%)$, were case series or case reports (78\%), and did not report a definition of the syndrome (85\%). Analytic designs (cohort, casecontrol) were used in only $19 \%$ of studies. The topics most frequently considered were clinical semiology (71\%), neurophysiology (68\%), etiology (64\%), therapy $(51 \%)$, and genetics $(36 \%)$. Only $9 \%$ of the studies addressed epidemiology, diagnosis, or prognosis.

NOMENCLATURE The 2 major outcomes of the consensus conference were the need to change nomenclature and the need to recognize the disorder as a distinct epilepsy syndrome.

The new name proposed is sleep-related hypermotor epilepsy (SHE). Although the name NFLE has historical significance, 3 critical issues (discussed and referenced below), justified this change. First, the term nocturnal was considered misleading because it implies a chronobiological pattern of seizure occurrence, whereas evidence indicates that occurrence in sleep is the most important characteristic, whether at night or during daytime naps. Second, the emphasis on localization to the frontal lobe was considered misleading in view of evidence that the characteristic seizures may also arise from other cerebral regions. Third, the original name did not specify the typical clinical semiology involved, which consists primarily of hypermotor seizures, and may also include attacks with predominantly tonic or dystonic features. In proposing this name, the consensus panel recognized a logical inconsistency in that the term hypermotor describes a seizure type rather than an epilepsy type; however, this is also true of several other widely accepted syndrome names (e.g., progressive myoclonus epilepsy, childhood absence epilepsy). The consensus was that the simplicity and ease of recall of SHE was more important than this concern. In addition, although the consensus panel acknowledged that the clinical semiology of the syndrome is not fully captured by "hypermotor," they accepted this term because the full syndrome description incorporates additional details about clinical presentation.

At the present state of knowledge, SHE is best regarded as a single syndrome; neither constellations of clinical features nor presence of comorbidities yet justifies the delineation of separate syndromes within SHE. Although SHE has diverse etiologies, it is defined by clinical manifestations (hypermotor seizures) possibly resulting from shared downstream mechanisms occurring during sleep/wake oscillation changes, suggesting a unique pathogenic network. ${ }^{10,11, e 6}$ Moreover, consideration of SHE as a single syndrome is most useful in clinical practice, because the syndrome requires a distinct diagnostic and therapeutic approach.

So far, only the autosomal dominant form of the syndrome (previously ADNFLE) is included within the guidelines proposed by the International League Against Epilepsy Commission on Classification and Terminology. ${ }^{12}$ Thus, the description of SHE within this article expands the phenotype and clarifies identifying features of this syndrome on the basis of available evidence.

CLINICAL FEATURES Statements regarding clinical features of SHE were formulated based on core literature consisting of studies of Class III level ${ }^{7,13-16}$ or Class IV level. ${ }^{5,17-19}$

- SHE is characterized by the occurrence of brief $(<2$ minutes) seizures with stereotyped motor patterns within individuals and abrupt onset and offset. ${ }^{5,7,13-19}$ 


\begin{tabular}{|c|c|c|c|c|c|c|c|c|c|c|}
\hline \multirow{2}{*}{$\begin{array}{l}\text { Table } \\
\text { Topic }\end{array}$} & \multicolumn{10}{|c|}{ criptive features of published studies on sleep-related hypermotor epilepsy (SHE) ${ }^{a}$-related topics } \\
\hline & $\begin{array}{l}\text { All studies, } \\
\text { n (\%) }\end{array}$ & $\begin{array}{l}\text { Studies with } \geq 10 \\
\text { patients, } \mathrm{n}(\%)\end{array}$ & $\mathrm{Age}^{\mathrm{b}} \mathrm{n}(\%)$ & $\begin{array}{l}\text { ADSHE/SHE, } \\
\text { n (\%) }\end{array}$ & $\begin{array}{l}\text { Definition of SHE } \\
\text { reported, } \mathrm{n}(\%)\end{array}$ & $\begin{array}{l}\text { Cohort } \\
\text { studies, n (\%) }\end{array}$ & $\begin{array}{l}\text { Case-control } \\
\text { studies, } \mathrm{n}(\%)\end{array}$ & $\begin{array}{l}\text { Cross-sectional } \\
\text { studies, n (\%) }\end{array}$ & $\begin{array}{l}\text { Case series/family } \\
\text { series, } n(\%)\end{array}$ & $\begin{array}{l}\text { Case report/family } \\
\text { reports, } n(\%)\end{array}$ \\
\hline All studies & $197(100)$ & $85(43)$ & $\begin{array}{l}74 \text { (38) children, } 155 \\
\text { (79) adults }\end{array}$ & $\begin{array}{l}79 \text { (40) ADSHE, } \\
105 \text { (53) SHE }\end{array}$ & $30(15)$ & 6 (3) & $31(16)$ & $6(3)$ & $96(49)$ & $58(29)$ \\
\hline Proof-of-concept & $25(13)$ & $10(40)$ & $\begin{array}{l}10(40) \text { children, } 21 \\
(84) \text { adults }\end{array}$ & - & $1(4)$ & - & $2(8)$ & - & $7(28)$ & $16(64)$ \\
\hline Boundary topics & $25(13)$ & $9(36)$ & $\begin{array}{l}12 \text { (48) children, } 20 \\
\text { (80) adults }\end{array}$ & - & $5(20)$ & 2 (8) & $1(4)$ & - & $13(52)$ & 9 (36) \\
\hline Etiology & $127(64)$ & $52(41)$ & $\begin{array}{l}52(41) \text { children, } 95 \\
\text { (75) adults }\end{array}$ & $\begin{array}{l}61 \text { (48) ADSHE, } 67 \\
\text { (53) SHE }\end{array}$ & $20(16)$ & 4 (3) & $12(9)$ & 2 (2) & $65(51)$ & 44 (34) \\
\hline Genetic & $71(36)$ & 39 (55) & $\begin{array}{l}24 \text { (34) children, } 57 \\
\text { (80) adults }\end{array}$ & $\begin{array}{l}60 \text { (85) ADSHE, } 17 \\
\text { (24) SHE }\end{array}$ & $5(7)$ & - & 11 (15) & - & $43(61)$ & $17(24)$ \\
\hline Epidemiology & $2(1)$ & $2(100)$ & $\begin{array}{l}1(50) \text { children, } 2 \\
(100) \text { adults }\end{array}$ & 2 (100) SHE & $2(100)$ & - & $2(100)$ & - & - & - \\
\hline Clinical features & $140(71)$ & $52(37)$ & $\begin{array}{l}55 \text { (39) children, } 115 \\
\text { (82) adults }\end{array}$ & $\begin{array}{l}53 \text { (38) ADSHE, } 83 \\
\text { (59) SHE }\end{array}$ & $20(14)$ & $2(1)$ & $12(9)$ & 1 (1) & $75(54)$ & $50(36)$ \\
\hline $\begin{array}{l}\text { Electroclinical } \\
\text { features }\end{array}$ & $133(68)$ & 44 (33) & $\begin{array}{l}55 \text { (41) children, } 107 \\
\text { (80) adults }\end{array}$ & $\begin{array}{l}41 \text { (31) ADSHE, } 79 \\
\text { (59) SHE }\end{array}$ & $20(15)$ & 1 (1) & $12(9)$ & 3 (2) & $71(53)$ & 46 (35) \\
\hline Diagnosis & $8(4)$ & $6(75)$ & $\begin{array}{l}4(50) \text { children, } 7 \text { (88) } \\
\text { adults }\end{array}$ & $\begin{array}{l}2 \text { (25) ADSHE, } 7 \\
\text { (88) SHE }\end{array}$ & 3 (38) & $1(13)$ & $4(50)$ & $2(25)$ & $1(13)$ & - \\
\hline Prognosis & $8(4)$ & $7(88)$ & $\begin{array}{l}3(38) \text { children, } 8 \\
(100) \text { adults }\end{array}$ & $\begin{array}{l}2 \text { (25) ADSHE, } 4 \\
\text { (50) SHE }\end{array}$ & $4(50)$ & $2(25)$ & 3 (38) & 1 (1) & $2(25)$ & - \\
\hline Therapy & $100(51)$ & $28(28)$ & $\begin{array}{l}43(43) \text { children, } 82 \\
\text { (82) adults }\end{array}$ & $\begin{array}{l}29 \text { (29) ADSHE, } 64 \\
\text { (64) SHE }\end{array}$ & $16(16)$ & $1(1)$ & 5 (5) & - & $49(49)$ & $45(45)$ \\
\hline
\end{tabular}

a SHE/autosomal dominant SHE = nocturnal frontal lobe epilepsy/autosomal dominant nocturnal frontal lobe epilepsy.

${ }^{b}$ Number of studies including children or adults. Some studies included both, or did not specify any age.

${ }^{\mathrm{c}}$ Number of studies including ADSHE or SHE patients. Some studies included both, or did not report any diagnostic label. 
- The most common clinical expression consists of "hypermotor" events. $5,7,13-15,17-19$

- Seizures of SHE occur predominantly during sleep; however, seizures during wakefulness may also occur. ${ }^{5,17-19}$

SHE is a rare form of focal epilepsy, with an estimated minimum prevalence of 1.8/100,000 individuals, fulfilling the definition of rare disease. ${ }^{20} \mathrm{SHE}$ affects both sexes, and involves sleep-related seizures with various motor manifestations., ${ }^{5,17}$ Seizure onset may be at any age with a peak during childhood and adolescence. ${ }^{5,17}$ Seizure frequency may be very high, with occurrence either every night or almost every night, usually many times per night. ${ }^{13,17}$ Clustering is characteristic but not obligatory for diagnosis. Seizures occur predominantly during sleep (and consequently most commonly during the night), primarily in nonREM (NREM) sleep and rarely during REM sleep. Seizures during active wakefulness may also occasionally occur during the patient's lifetime. The first occurrence of these seizures may precede, coincide, or follow the onset of sleep-related seizures. ${ }^{17}$

Seizures are abrupt in onset and offset, typically brief ( $<2$ minutes), and have a highly stereotyped motor pattern within individuals. ${ }^{13-15,17}$ The primary clinical expression consists of "hypermotor" events, ${ }^{21}$ characterized by vigorous hyperkinetic features (complex body movements with kicking or cycling of limbs and rocking body movements ${ }^{7}$ ), usually with vegetative signs, vocalization, and emotional facial expression. ${ }^{7,17}$ Asymmetric tonic/dystonic seizures with or without head/eye deviation are also observed., ${ }^{5,17}$

Seizures may be preceded by abrupt arousal or a distinct aura. ${ }^{5,18}$ Awareness of episodes is not uncommon. ${ }^{18,22}$ Typically, patients with SHE present a series of sleep-related motor events becoming increasingly long and complex, even on the same night. Clinical features range from brusque stereotyped arousals (i.e., paroxysmal arousal ${ }^{17}$ or minor motor events ${ }^{23}$ ), repeated throughout the night or arising intermittently, with an almost periodic pattern, to complex hypermotor seizures as described above and, more seldom, protracted ambulatory behavior known as epileptic nocturnal wandering. ${ }^{17,22,24,25}$ These events can last longer than 2 minutes. These different seizure manifestations tend to coincide in the same patient, with the shorter events developing into more prolonged and complex attacks. ${ }^{17,22} \mathrm{~Pa}$ tients with SHE may complain of unsatisfactory sleep and daytime tiredness. However, they do not have significantly more daytime sleepiness than controls. ${ }^{26}$

Distinction from arousal parasomnias usually relies on clinical history (frequency, clustering, and timing with respect to sleep onset of the attacks), ${ }^{16}$ even though EEG-polysomnography (PSG) may be required in some challenging cases. A personal or familial history of arousal parasomnias is common in patients with SHE, making shared pathophysiologic pathways plausible in these conditions. ${ }^{27,28}$

The majority of patients have normal intelligence. However, intellectual disability and behavior disorders have been reported in $\mathrm{SHE},{ }^{29}$ especially in the familial form related to mutations in $K C N T 1,{ }^{30}$ and consequently are not exclusion criteria for SHE.

Response to medication has not been systematically investigated. Carbamazepine is effective at low doses in some patients with SHE, but this therapy seems to be ineffective in at least one-third of patients, ${ }^{17}$ making the response to antiepileptic drugs not discriminant for SHE diagnosis. Surgery has been found to be effective in some patients with severe, drug-resistant SHE related to focal cortical dysplasia. ${ }^{13,31}$ Suspicion of a genetic cause does not contraindicate presurgical evaluation, although data are still lacking on surgical outcomes in patients with mutations in known genes.

ELECTROCLINICAL FEATURES Statements regarding the electroclinical features of seizures in SHE are based on core literature consisting of Class III level ${ }^{13,16}$ or Class IV level ${ }^{5,17,19,22,32-36}$ studies.

- Interictal and ictal scalp EEG features may be uninformative. . $^{13,17,19}$

- Prolonged video-EEG recording is the best available diagnostic test to assess the occurrence of seizures ${ }^{13,16}$ but, if negative, does not rule out the diagnosis because seizures may not be recorded and interictal EEG abnormalities may be absent. 5,13,17,19

- Sleep-related hypermotor seizures may arise from various frontal as well as from extrafrontal areas. $^{22,32-36}$

In many patients with $\mathrm{SHE}$, the interictal and ictal scalp EEG features are uninformative, especially when seizures originate from the deep-seated cortex. $^{13,17}$ Prolonged video-EEG or, if available, PSG recording, is the best tool to assess seizure occurrence and is obligatory to characterize the abnormalities in patients undergoing presurgical investigation. ${ }^{13}$ Sleep staging by PSG may serve to differentiate SHE seizures from NREM parasomnias, the latter usually arising from stage 3 NREM sleep, even though this is not a major element for the differential diagnosis.

PSG recordings show that increased sleep instability is very common, particularly when multiple events occur during sleep. ${ }^{10,25,37}$ Some studies suggest that macrostructural sleep disturbances and arousal instability are part of the syndrome but this needs further investigation. ${ }^{10,22,37}$

Intracranial recordings performed in drug-resistant patients with SHE have clearly demonstrated that ictal 
discharge may arise not only from frontal lobe $e^{13,32}$ but also from various extrafrontal areas, including insulo-opercular, ${ }^{33,34}$ temporal, ${ }^{35}$ and parietal ${ }^{36}$ cortices, then propagating to frontal cortex and resulting in hypermotor seizures. ${ }^{\mathrm{e} 6}$ This might suggest the ictal involvement of common cortico-subcortical networks $s^{\mathrm{e}, \mathrm{e} 8}$ or a release phenomenon of stereotyped inborn fixed motor patterns. ${ }^{11}$

DIAGNOSTIC CERTAINTY Criteria for diagnostic certainty of SHE were developed based on consensus expert opinions and studies of Class III level. ${ }^{13,16,38}$

- Diagnosis of SHE is primarily based on clinical history. The absence of clear interictal and ictal EEG correlates, both during wakefulness and sleep, does not exclude the diagnosis of SHE. ${ }^{13}$

- Certainty of diagnosis can be categorized into 3 levels: witnessed (possible) SHE, videodocumented (clinical) SHE, and video-EEGdocumented (confirmed) SHE.

Witnessed (possible) SHE. The main prerequisite to suspect the diagnosis of SHE is the presence of seizures consisting of obvious and disruptive hypermotor events, as described above. The semiologic aspects of such events, as provided by an eyewitness, are generally concordant with those documented by video analysis. ${ }^{16}$ Hence, data from a good clinical history are sufficient to make the diagnosis of witnessed (possible) SHE.

Video-documented (clinical) SHE. Clinically diagnosed SHE requires audio-video documentation of hypermotor events. In such a video recording, at least 1 event but preferably 2 entire events should be documented (confirmed to be typical by witness), including the onset and with clear visualization of the entire events, showing the evolution and offset of the attacks. If the captured episodes are minor motor events or paroxysmal arousals, and if few episodes are captured, the clinical diagnosis may be unreliable. ${ }^{16,38,39}$

Video-EEG-documented (confirmed) SHE. A confirmed diagnosis of SHE requires video-EEG documentation of the events during a daytime sleep recording after sleep deprivation, or during a full night sleep recording, with at least 19 EEG channels (10-20 International System), ECG, oculogram, and chin EMG. SHE is confirmed when hypermotor seizures are recorded during sleep, associated with a clear-cut epileptic discharge or with interictal epileptiform abnormalities.

ETIOLOGY/GENETICS Statements about etiology were formulated based on core literature consisting of clinical studies of Class III level ${ }^{5,18,31,40}$ and Class
IV level ${ }^{17,19}$ or genetic molecular studies of Class 1 level, ${ }^{41,42}$ Class 2 level, ${ }^{6,30,43}$ or Class 3 level. ${ }^{44,45}$

- In a majority of patients, the etiology is unknown. ${ }^{17}$

- Identified etiologies are heterogeneous and include structural anomalies such as focal cortical dysplasia, acquired injuries, and genetic causes. ${ }^{5,6,18,30,31,40-45}$

- No specific clinical features distinguish etiologies. ${ }^{5,17,19}$

A majority of individuals with SHE do not have a family history or other identified etiologies. In some patients with drug-resistant SHE, the etiology may involve a surgically treatable lesion, in particular type II focal cortical dysplasia. ${ }^{31,40}$

Familial and sporadic SHE show similar clinical features. ${ }^{5,17,19}$ Autosomal dominant SHE (ADSHE; previously ADNFLE) is characterized by marked intrafamilial variation in severity. ${ }^{18} \mathrm{~A}$ minority of familial cases has a known genetic mutation. While de novo mutations were first identified in rare cases more than a decade ago, ${ }^{44}$ few sporadic cases have a known genetic cause. Even in cases with a family history, an autosomal dominant pattern of inheritance is not frequent; the mode of inheritance is unclear in most cases.

It was in ADSHE that the first epilepsy gene, CHRNA4, was discovered. ${ }^{6,18}$ This was the first of 3 genes encoding subunits of the neuronal acetylcholine receptor (nAChR) to be implicated in ADSHE (CHRNB2, CHRNA2). ${ }^{41,42}$ The phenotype produced by mutations of the $3 \mathrm{nAChR}$ subunit genes is generally indistinguishable. ${ }^{46} \mathrm{~A}$ more severe form of ADSHE has been described in which some individuals have intellectual disability, regression, and behavioral and psychiatric disorders (depression, psychosis, aggression, and personality disorder). ${ }^{29}$ Severe ADSHE has been associated with mutations of the sodium-activated potassium channel encoded by KCNT1. ${ }^{30}$ Interestingly, the same gene is mutated in a far more severe epileptic encephalopathy, epilepsy with migrating focal seizures of infancy (MFSI). ${ }^{47}$ Functional studies show phenotype-genotype correlation with a greater gain of function in MFSI than in ADSHE. $^{48}$

In some families with ADSHE, mutations have been found in DEPDC5, a gene originally implicated in familial focal epilepsy with variable foci (FFEVF). ${ }^{49,50}$ SHE has long been recognized as a phenotype within $\mathrm{FFEVF}^{51}$ and in some families, especially smaller ones, the phenotype may be exclusively SHE. ${ }^{43,45,50}$ DEPDC5 encodes a repressor of the mammalian target of rapamycin (mTOR) pathway, a key regulator of cell growth. ${ }^{52}$ This newly recognized component of the mTOR pathway means that 
this pathway may be more critical to common focal epilepsy than previously appreciated, suggesting that mTOR inhibitors, which are effective in the archetypal mTORpathy, tuberous sclerosis, may have more widespread application in focal epilepsies. ${ }^{53}$

RESEARCH NEEDS The main research gaps in SHE regard epidemiology, pathophysiology, prognosis, genetics, and targeted therapy.

Population-based studies are needed to estimate the incidence and prevalence of $\mathrm{SHE}^{20}$ and could also be used to provide critical information about prognosis and remission rates, comorbidities, and mortality compared to other focal epilepsies. Multicenter studies of the familial co-occurrence of SHE with arousal parasomnias are needed to elucidate potential shared genetic susceptibility to these 2 disorders. ${ }^{27}$

In a retrospective cohort of patients with SHE, incidence of sudden unexpected death in epilepsy (SUDEP) was 0.36 per 1,000 person-years, not higher than in prevalent epilepsy populations. ${ }^{54}$ This paucity of reported SUDEP in SHE is notable, given the daily occurrence of seizures during sleep and the previous demonstration that occurrence of nocturnal seizures is a risk factor for SUDEP after adjustment for generalized tonic-clonic seizures. ${ }^{55}$ The lower than expected risk of SUDEP in SHE might reflect a low occurrence of generalized tonic-clonic seizures in SHE. ${ }^{54}$

Improved structured instruments for clinical diagnosis of SHE are needed for epidemiologic and genetic studies. Multicenter studies are needed to elucidate the SHE spectrum and natural history, ranging from clear-cut cases to atypical forms overlapping with parasomnias. Home video recordings during sleep may also have utility for improving diagnostic accuracy, and additional multicenter studies are needed to validate this approach. Although a key role of genetic factors is well-known in autosomal dominant SHE, a minority of familial cases and rare sporadic cases have a known genetic cause. Nextgeneration sequencing will enable the identification of additional susceptibility genes in SHE, and the frequency of mutations in specific genes can subsequently be established through targeted mutation testing in large cohorts. Family studies may also provide insights into genetically based phenotypic variation and alternative inheritance patterns of SHE such as recessive or polygenic models.

The increasingly recognized role of de novo and somatic mutations in human disease is highly relevant to SHE. ${ }^{56}$ Sporadic cases may have de novo mutations of genes with high penetrance or genes with smaller effects conferring risk in polygenic or multifactorial settings. The identification of postzygotic, somatic mutations in brain as causes of malformations such as hemimegalencephaly ${ }^{57,58}$ suggests that other brain diseases may be due to somatic mutations. Such mutations may be identifiable only in brain tissue from patients undergoing epilepsy surgery, or may be present in other tissues such as blood and saliva due to mosaicism.

Some individuals in families with DEPDC5 mutations have malformations of cortical development, especially focal cortical dysplasia. ${ }^{59}$ Given the role of $D E P D C 5$ as an inhibitor of the mTOR pathway, a key question is whether a second-hit mutation is present in the brain tissue of an individual with a DEPDC5 mutation. This can be addressed with whole-exome sequencing of tissue removed for refractory epilepsy and may improve understanding of the molecular pathology of malformations of cortical development.

Finally, genetic findings may serve as the basis for development of targeted therapies for SHE. An early example of the potential of this approach is the successful use of quinidine for treatment of a patient with an epileptic encephalopathy caused by a de novo KCNT1 mutation, ${ }^{60}$ following the finding that it reverses the gain of function of the mutant potassium channel in vitro. ${ }^{30,48}$ These and similar developments provide promise for understanding and precision medicine strategies for treatment of this intriguing syndrome.

\section{AUTHOR CONTRIBUTIONS}

Scientific Committee: P. Tinuper (Chair), S.F. Berkovic, L. Nobili, F. Bisulli, L. Vignatelli. Systematic Review and Technical Committee: L. Vignatelli, L. Licchetta, B. Mostacci, I. Naldi. Consensus Panel: R. Ottman (Chair), P. Tinuper, S.F. Berkovic, L. Nobili, C. Bassetti, M.W. Mahowald, F. Vigevano, M. Pugliatti. Clinical History Group: F. Cirignotta, J.H. Cross, C.P. Derry, D. Hesdorffer, R. Manni, F. Provini. Electroclinical Investigations Group: P. Halasz, P. Kahane, L. Parrino, L. Tassi, M. Zucconi. Etiology Group: A. Gambardella, R. Guerrini, C. Marini, F. Picard, P. Ryvlin, I.E. Scheffer. Writing Committee: P. Tinuper (corresponding author), R. Ottman, S.F. Berkovic, L. Vignatelli, F. Bisulli, D. Hesdorffer, I.E. Scheffer, J.H. Cross, P. Kahane, L. Nobili, L. Tassi, F. Provini.

\section{ACKNOWLEDGMENT}

This article is dedicated to the memory of our teacher, Prof. Elio Lugaresi (1926-2015), a pioneering researcher in the field of sleep medicine/ nocturnal seizures.

\section{STUDY FUNDING}

Supported by IRCCS Institute of Neuroscience of Bologna, Cyberonics, UCB Pharma, EISAI, and Ecupharma. P. Tinuper, L. Licchetta, B. Mostacci, and F. Bisulli are recipients of a Telethon grant (GGP13200 to P.T.) for research into nocturnal seizures.

\section{DISCLOSURE}

The authors report no disclosures relevant to the manuscript. Go to Neurology.org for full disclosures.

Received August 21, 2015. Accepted in final form January 27, 2016.

\section{REFERENCES}

1. Lugaresi E, Cirignotta F. Hypnogenic paroxysmal dystonia: epileptic seizure or a new syndrome? Sleep 1981;4: 129-138. 
2. Williamson PD, Spencer DD, Spencer SS, Novelly RA, Mattson RH. Complex partial seizures of frontal lobe origin. Ann Neurol 1985;18:497-504.

3. Waterman K, Purves SJ, Kosaka B, Strauss E, Wada JA. An epileptic syndrome caused by mesial frontal lobe seizure foci. Neurology 1987;37:577-582.

4. Tinuper P, Cerullo A, Cirignotta F, Cortelli P, Lugaresi E, Montagna P. Nocturnal paroxysmal dystonia with shortlasting attacks: three cases with evidence for an epileptic frontal lobe origin of seizures. Epilepsia 1990;31:549-556.

5. Scheffer IE, Bhatia KP, Lopes-Cendes I, et al. Autosomal dominant frontal epilepsy misdiagnosed as sleep disorder. Lancet 1994;343:515-517.

6. Steinlein OK, Mulley JC, Propping P, et al. A missense mutation in the neuronal nicotinic acetylcholine receptor alpha 4 subunit is associated with autosomal dominant nocturnal frontal lobe epilepsy. Nat Genet 1995;11: 201-203.

7. Bisulli F, Vignatelli L, Naldi I, et al. Diagnostic accuracy of a structured interview for nocturnal frontal lobe epilepsy (SINFLE): a proposal for developing diagnostic criteria. Sleep Med 2012;13:81-87.

8. Candiani G, Colombo C, Daghini R, et al. Manuale metodologico: come organizzare una conferenza di consenso [online]. Rome: Istituto Superiore di Sanità, Sistema Nazionale Linee Guida SNLG; 2009. Available at: http://www.snlg-iss.it/manuale_metodologico_consensus. Accessed January 2, 2015.

9. American College of Chest Physicians. ACCP Consensus Statement Development Guide [online]. Available at: http://www.accpstorage.org/newOrganization/guidelines/ ConsensusGuide.pdf. Accessed September 18, 2014.

10. Parrino L, De Paolis F, Milioli G, et al. Distinctive polysomnographic traits in nocturnal frontal lobe epilepsy. Epilepsia 2012;53:1178-1184.

11. Tassinari CA, Cantalupo G, Hogl B, et al. Neuroethological approach to frontolimbic epileptic seizures and parasomnias: the same central pattern generators for the same behaviours. Rev Neurol 2009;165:762-768.

12. Berg AT, Berkovic SF, Brodie MJ, et al. Revised terminology and concepts for organization of seizures and epilepsies: report of the ILAE Commission on Classification and Terminology, 2005-2009. Epilepsia 2010;51:676-685.

13. Nobili L, Francione S, Mai R, et al. Surgical treatment of drug-resistant nocturnal frontal lobe epilepsy. Brain 2007; 130:561-573.

14. Derry CP, Davey M, Johns M, et al. Distinguishing sleep disorders from seizures: diagnosing bumps in the night. Arch Neurol 2006;63:705-709.

15. Manni R, Terzaghi M, Repetto A. The FLEP scale in diagnosing nocturnal frontal lobe epilepsy, NREM and REM parasomnias: data from a tertiary sleep and epilepsy unit. Epilepsia 2008;49:1581-1585.

16. Derry CP, Harvey AS, Walker MC, Duncan JS, Berkovic SF. NREM arousal parasomnias and their distinction from nocturnal frontal lobe epilepsy: a video EEG analysis. Sleep 2009;32:1637-1644.

17. Provini F, Plazzi G, Tinuper P, Vandi S, Lugaresi E, Montagna P. Nocturnal frontal lobe epilepsy: a clinical and polygraphic overview of 100 consecutive cases. Brain 1999;122:1017-1031.

18. Scheffer IE, Bhatia KP, Lopes-Cendes I, et al. Autosomal dominant nocturnal frontal lobe epilepsy: a distinctive clinical disorder. Brain 1995;118:61-73.
19. Oldani A, Zucconi M, Asselta R, et al. Autosomal dominant nocturnal frontal lobe epilepsy: a videopolysomnographic and genetic appraisal of 40 patients and delineation of the epileptic syndrome. Brain 1998; 121:205-223.

20. Vignatelli L, Bisulli F, Giovannini G, et al. Prevalence of nocturnal frontal lobe epilepsy in the adult population of Bologna and Modena, Emilia-Romagna Region, Italy. Sleep 2015;38:479-485.

21. Luders H, Acharya J, Baumgartner C, et al. Semiological seizure classification. Epilepsia 1998;39:1006-1013.

22. Nobili L, Francione S, Mai R, et al. Nocturnal frontal lobe epilepsy: intracerebral recordings of paroxysmal motor attacks with increasing complexity. Sleep 2003;26:883886.

23. Terzaghi M, Sartori I, Mai R, et al. Sleep-related minor motor events in nocturnal frontal lobe epilepsy. Epilepsia 2007; $48: 335-341$.

24. Montagna P. Nocturnal paroxysmal dystonia and nocturnal wandering. Neurology 1992;42:61-67.

25. Terzaghi M, Sartori I, Mai R, et al. Coupling of minor motor events and epileptiform discharges with arousal fluctuations in NFLE. Epilepsia 2008;49:670-676.

26. Vignatelli L, Bisulli F, Naldi I, et al. Excessive daytime sleepiness and subjective sleep quality in patients with nocturnal frontal lobe epilepsy: a case-control study. Epilepsia 2006;47(suppl 5):73-77.

27. Bisulli F, Vignatelli L, Naldi I, et al. Increased frequency of arousal parasomnias in families with nocturnal frontal lobe epilepsy: a common mechanism? Epilepsia 2010;51: 1852-1860.

28. Bassetti C, Vella S, Donati F, Wielepp P, Weder B. SPECT during sleepwalking. Lancet 2000;356:484-485.

29. Derry CP, Heron SE, Phillips F, et al. Severe autosomal dominant nocturnal frontal lobe epilepsy associated with psychiatric disorders and intellectual disability. Epilepsia 2008;49:2125-2129.

30. Heron SE, Smith KR, Bahlo M, et al. Missense mutations in the sodium-gated potassium channel gene KCNT1 cause severe autosomal dominant nocturnal frontal lobe epilepsy. Nat Genet 2012;44:1188-1190.

31. Tassi L, Garbelli R, Colombo N, et al. Electroclinical, MRI and surgical outcomes in 100 epileptic patients with type II FCD. Epileptic Disord 2012;14:257-266.

32. Rheims S, Ryvlin P, Scherer C, et al. Analysis of clinical patterns and underlying epileptogenic zones of hypermotor seizures. Epilepsia 2008;49:2030-2040.

33. Proserpio P, Cossu M, Francione S, et al. Insular-opercular seizures manifesting with sleep-related paroxysmal motor behaviors: a stereo-EEG study. Epilepsia 2011;52:17811791.

34. Ryvlin P, Minotti L, Demarquay G, et al. Nocturnal hypermotor seizures, suggesting frontal lobe epilepsy, can originate in the insula. Epilepsia 2006;47:755-765.

35. Nobili L, Cossu M, Mai R, et al. Sleep-related hyperkinetic seizures of temporal lobe origin. Neurology 2004;62: 482-485.

36. Montavont A, Kahane P, Catenoix H, et al. Hypermotor seizures in lateral and mesial parietal epilepsy. Epilepsy Behav 2013;28:408-412.

37. Zucconi M, Oldani A, Smirne S, Ferini-Strambi L. The macrostructure and microstructure of sleep in patients with autosomal dominant nocturnal frontal lobe epilepsy. J Clin Neurophysiol 2000;17:77-86. 
38. Vignatelli L, Bisulli F, Provini F, et al. Interobserver reliability of video recording in the diagnosis of nocturnal frontal lobe seizures. Epilepsia 2007;48:1506-1511.

39. Bisulli F, Vignatelli L, Provini F, Leta C, Lugaresi E, Tinuper P. Parasomnias and nocturnal frontal lobe epilepsy (NFLE): lights and shadows: controversial points in the differential diagnosis. Sleep Med 2011;12(suppl 2):S27-S32.

40. Nobili L, Cardinale F, Magliola U, et al. Taylor's focal cortical dysplasia increases the risk of sleep-related epilepsy. Epilepsia 2009;50:2599-2604.

41. De Fusco M, Becchetti A, Patrignani A, et al. The nicotinic receptor beta 2 subunit is mutant in nocturnal frontal lobe epilepsy. Nat Genet 2000;26:275-276.

42. Aridon P, Marini C, Di Resta C, et al. Increased sensitivity of the neuronal nicotinic receptor alpha 2 subunit causes familial epilepsy with nocturnal wandering and ictal fear. Am J Hum Genet 2006;79:342-350.

43. Picard F, Makrythanasis P, Navarro V, et al. DEPDC5 mutations in families presenting as autosomal dominant nocturnal frontal lobe epilepsy. Neurology 2014;82:2101-2106.

44. Phillips HA, Marini C, Scheffer IE, Sutherland GR, Mulley JC, Berkovic SF. A de novo mutation in sporadic nocturnal frontal lobe epilepsy. Ann Neurol 2000;48:264267.

45. Ishida S, Picard F, Rudolf G, et al. Mutations of DEPDC5 cause autosomal dominant focal epilepsies. Nat Genet 2013;45:552-555.

46. McLellan A, Phillips HA, Rittey C, et al. Phenotypic comparison of two Scottish families with mutations in different genes causing autosomal dominant nocturnal frontal lobe epilepsy. Epilepsia 2003;44:613-617.

47. Barcia G, Fleming MR, Deligniere A, et al. De novo gainof-function KCNT1 channel mutations cause malignant migrating partial seizures of infancy. Nat Genet 2012;44: $1255-1259$.

48. Milligan CJ, Li M, Gazina EV, et al. KCNT1 gain of function in 2 epilepsy phenotypes is reversed by quinidine. Ann Neurol 2014;75:581-590.

49. Scheffer IE, Phillips HA, O’Brien CE, et al. Familial partial epilepsy with variable foci: a new partial epilepsy syndrome with suggestion of linkage to chromosome 2 . Ann Neurol 1998;44:890-899.

50. Dibbens LM, de Vries B, Donatello S, et al. Mutations in DEPDC5 cause familial focal epilepsy with variable foci. Nat Genet 2013;45:546-551.

51. Berkovic SF, Serratosa JM, Phillips HA, et al. Familial partial epilepsy with variable foci: clinical features and linkage to chromosome 22q12. Epilepsia 2004;45:10541060.

52. Bar-Peled L, Chantranupong L, Cherniack AD, et al. A tumor suppressor complex with GAP activity for the Rag GTPases that signal amino acid sufficiency to mTORC1. Science 2013;340:1100-1106.

53. Krueger DA, Wilfong AA, Holland-Bouley K, et al. Everolimus treatment of refractory epilepsy in tuberous sclerosis complex. Ann Neurol 2013;74:679-687.

54. Mostacci B, Bisulli F, Vignatelli L, et al. Incidence of sudden unexpected death in nocturnal frontal lobe epilepsy: a cohort study. Sleep Med 2015;16:232-236.

55. Lamberts RJ, Thijs RD, Laffan A, Langan Y, Sander JW. Sudden unexpected death in epilepsy: people with nocturnal seizures may be at highest risk. Epilepsia 2012;53:253257.

56. Poduri A, Evrony GD, Cai X, Walsh CA. Somatic mutation, genomic variation, and neurological disease. Science 2013;341:1237758.

57. Lee JH, Huynh M, Silhavy JL, et al. De novo somatic mutations in components of the PI3K-AKT3-mTOR pathway cause hemimegalencephaly. Nat Genet 2012;44: 941-945.

58. Poduri A, Evrony GD, Cai X, et al. Somatic activation of AKT3 causes hemispheric developmental brain malformations. Neuron 2012;74:41-48.

59. Scheffer IE, Heron SE, Regan BM, et al. Mutations in mammalian target of rapamycin regulator DEPDC5 cause focal epilepsy with brain malformations. Ann Neurol 2014;75:782-787.

60. Bearden D, Strong A, Ehnot J, Di Giovine M, Dlugos D, Goldberg EM. Targeted treatment of migrating partial seizures of infancy with quinidine. Ann Neurol 2014;76: 457-461. 


\section{Neurology}

\section{Definition and diagnostic criteria of sleep-related hypermotor epilepsy \\ Paolo Tinuper, Francesca Bisulli, J.H. Cross, et al.}

Neurology 2016;86;1834-1842 Published Online before print April 15, 2016

DOI 10.1212/WNL.0000000000002666

\section{This information is current as of April 15, 2016}

\section{Updated Information \&}

Services

Supplementary Material

References

Citations

Permissions \& Licensing

Reprints including high resolution figures, can be found at: http://n.neurology.org/content/86/19/1834.full

Supplementary material can be found at: http://n.neurology.org/content/suppl/2016/04/18/WNL.0000000000002 666.DC1

This article cites 58 articles, 5 of which you can access for free at: http://n.neurology.org/content/86/19/1834.full\#ref-list-1

This article has been cited by 3 HighWire-hosted articles: http://n.neurology.org/content/86/19/1834.full\#\#otherarticles

Information about reproducing this article in parts (figures,tables) or in its entirety can be found online at:

http://www.neurology.org/about/about_the_journal\#permissions

Information about ordering reprints can be found online:

http://n.neurology.org/subscribers/advertise

Neurology ${ }^{\circledR}$ is the official journal of the American Academy of Neurology. Published continuously since 1951, it is now a weekly with 48 issues per year. Copyright @ 2016 American Academy of Neurology. All rights reserved. Print ISSN: 0028-3878. Online ISSN: 1526-632X.

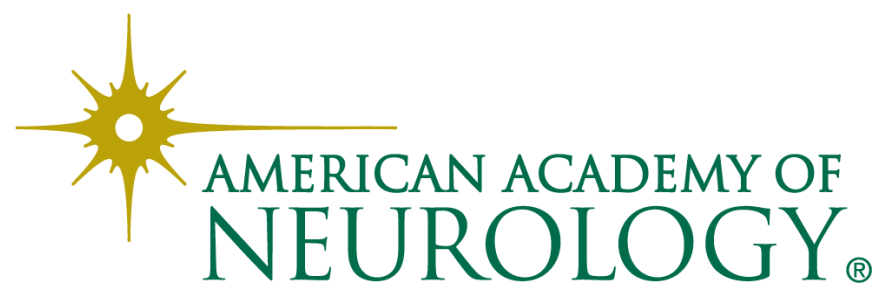

